\title{
TAK1 regulates SCF expression to modulate PKB $\alpha$ activity that protects keratinocytes from ROS-induced apoptosis
}

\author{
CRI Lam ${ }^{1,3}$, MJ Tan ${ }^{1,3}$, SH Tan $^{1,3}$, MBY Tang ${ }^{2}$, PCF Cheung ${ }^{1}$ and NS Tan ${ }^{\star, 1}$
}

Dysregulated reactive oxygen species (ROS) generation contributes to many human pathologies, including cancer and diabetes. During normal wound repair, inflammation-induced ROS production must be tightly controlled, but the mechanisms reining their generation remain unclear. Herein, we show that transforming growth factor $\beta$-activated kinase 1 (TAK1) directly regulates stem cell factor (SCF) expression, which activates the protein kinase B (PKB) $\alpha$ pro-survival pathway in a cell-autonomous manner to protect keratinocytes from ROS-mediated cell death. TAK1 is a pivotal inflammatory mediator whose expression was transiently elevated during wound healing, paralleling the ROS production profile. TAK1 deficiency in keratinocytes led to increased apoptosis in response to anoikis and TNF- $\alpha$ treatment and was associated with elevated ROS level as analyzed by FACS. Using organotypic skin co-culture and comparative growth factor array analysis, we revealed a cell-autonomous mechanism that involved the SCF/c-Kit/PKB $\alpha$ signaling cascade. Ectopic expression of TAK1 or treatment with exogenous recombinant SCF restored the increased ROS production and apoptotic cell death in TAK1-deficient keratinocytes. Conversely, normal keratinocytes treated with various inhibitors targeting the SCF/C-Kit/PKB $\alpha$ pathway exhibited increased ROS production and TNF- $\alpha$ - or anoikis-induced apoptosis. Our study reveals a novel anti-apoptotic role for SCF in keratinocytes and identifies TAK1 as a novel player uniting inflammation and ROS regulation in skin redox biology.

Cell Death and Differentiation (2011) 18, 1120-1129; doi:10.1038/cdd.2010.182; published online 14 January 2011

Wound healing comprises three progressive overlapping events: inflammation, re-epithelialization and tissue remodeling. Although wound healing is accompanied by inflammatory reactions, chronic inflammation impairs acute wound healing. Furthermore, prolonged inflammation has been the bane of chronic dermatological conditions like psoriasis ${ }^{1}$ and wound healing complications like non-healing diabetic wounds. ${ }^{2}$ It is thus of great importance to understand the underlying regulation of skin inflammation.

Reactive oxygen species (ROS) have profound effects on many biological processes, and thus it is crucial that ROS production be tightly controlled through a network of regulatory pathways. ${ }^{3}$ During normal wound healing, levels of the free radical superoxide peak at day 2 after injury in fullthickness excisional mouse wounds, as determined by redoxsensitive dye dihydroethidium and electron paramagnetic resonance. ${ }^{4}$ Low levels of and transient increases in ROS have antimicrobial action and operate through redox-sensitive signaling pathways and transcription factors to aid wound repair. ${ }^{5}$ However, excessive or persistently elevated ROS within the cells can significantly damage macromolecules or alter cellular functions, eventually leading to irreversible injury and cell death. Furthermore, a chronically deregulated state in which ROS signaling can up-regulate patterns of gene expression and cell responses are believed to significantly contribute to and/or sustain the pathogenesis of major human diseases characterized by chronic inflammation, chronic wound healing and tissue fibrogenesis. ${ }^{6}$ Despite the importance of balanced ROS production in wound healing, the mechanisms underlying this regulation need further study.

Transforming growth factor (TGF)- $\beta$-activated kinase 1 (TAK1) has been strongly implicated in skin inflammation. ${ }^{7}$ As a principle mediator of innate immunity, TAK1 serves as a key intermediate in proinflammatory pathways initiated by tumor necrosis factor (TNF)- $\alpha$ and interleukin (IL)-1. ${ }^{8}$ As a member of the MAPK kinase family, TAK1 can activate c-Jun $\mathrm{N}$-terminal kinase (JNK) and p38 MAPK through the stimulation of its downstream MAPK cascade. ${ }^{9}$ TAK1 also stimulates

\footnotetext{
${ }^{1}$ School of Biological Sciences, Nanyang Technological University, Singapore and ${ }^{2}$ National Skin Centre, Singapore

*Corresponding author: NS Tan, School of Biological Sciences, Nanyang Technological University, 60, Nanyang Drive, Singapore 637551, Singapore.

Tel: + 65 63162941; Fax: + 65 67913856; E-mail: nstan@ntu.edu.sg

${ }^{3}$ These authors contributed equally to this work.

Keywords: reactive oxygen species; stem cell factor; protein kinase B; autocrine

Abbreviations: AP-1, activating protein-1; Col, collagen; ChIP, chromatin immunoprecipitation; DAPI, 4',6-diamidino-2-phenylindole; DCF, dichlorodihydrofluorescein (CM-H2DCFDA); EMSA, electrophoretic mobility shift assay; FADD, Fas associated death domain; FLIP, FADD-like IL-1 $\beta$-converting enzyme)-inhibitory protein; GSK, glycogen synthase kinase; H\&E, hematoxylin and eosin staining; $l_{\kappa} \mathrm{B} \alpha$, nuclear factor of kappa light polypeptide gene enhancer in B-cells inhibitor, alpha; IKK $\beta$, inhibitor of nuclear factor kappa B kinase beta; JNK, c-Jun N-terminal kinase; $\mathrm{K}_{\mathrm{CTRL}}$, keratinocyte contro;; $\mathrm{K}_{\text {TAK1 }}$, keratinocyte with TAK1 knockdown; NAC, $\mathrm{N}$-acetylcysteine; OTC, organotypic skin co-culture; PCNA, proliferating cell nuclear antigen; PDGF, platelet derived growth factor; PI3K, phosphoinositide-3 kinase; $\mathrm{PKB} \alpha$, protein kinase $\mathrm{B} \alpha$; ROS, reactive oxygen species; SCF, stem cell factor; siRNA, small interfering ribonucleic acid; TAK1, transforming growth factor $\beta$-activated kinase 1; TGF- $\beta$, transforming growth factor- $\beta$; TNF- $\alpha$, tumor necrosis factor- $\alpha$; TRAIL, TNF-related apoptosis-inducing ligand; TUNEL, terminal deoxynucleotidyl transferase dUTP nick end labeling

Received 11.6.10; revised 04.11.10; accepted 06.12.10; Edited by P Vandenabeele; published online 14.1.11
} 
the $I_{\kappa} \mathrm{B} \alpha$ kinase cascade, leading to the activation of $\mathrm{NF}-\kappa \mathrm{B} .{ }^{10}$ In the skin, these downstream mediators of TAK1 are important for the maintenance of epidermal homeostasis. ${ }^{10,11}$ Perturbations to the JNK pathway have been implicated in epidermal hyperplasia leading to cancer development, while reduced NF- $\kappa \mathrm{B}$ function is linked to epidermal squamous cell carcinoma. Blocking the NF- $\kappa \mathrm{B}$ pathway through $\mathrm{IKK} \beta$ or IKK $\gamma$ inactivation also leads to severe skin inflammation. ${ }^{12,13}$ Mice with keratinocyte-specific deletion of TAK1 develop severe skin inflammation, characterized by massive cellular apoptosis, and die at postnatal day $7{ }^{7,14}$ Histological examination of TAK1-null mouse skin has revealed a dysregulated differentiation and increased keratinocyte proliferation, similarly observed in TAK1-deficient human keratinocytes. Given the central role that TAK1 has in inflammation, it has recently been implicated in ROS production. Indeed, TAK1-deficient mouse keratinocytes are more susceptible to TNF- $\alpha$ mediated apoptosis associated with increased ROS production, which can be abrogated via c-Jun-dependent mechanism. ${ }^{15}$ Taken together, these observations suggest that TAK1 has a homeostatic role in modulating ROS production in wound healing, but the precise underlying mechanism remains unknown.

Herein, we provide mechanistic insight into the TAK1regulated inhibition of TNF- $\alpha$-mediated apoptosis in human keratinocytes. More importantly, we reveal that this protective role of TAK1 occurs in a cell-autonomous manner via the autocrine action of stem cell factor (SCF). The expression of SCF in keratinocytes is transcriptionally regulated via the TAK1/ JNK/c-Jun signaling pathway. These findings identify a novel role for SCF in modulating the ROS level of keratinocytes.

\section{Results}

Elevated ROS production in wound epithelia. We have previously provided in vivo evidence that the expression of TAK1 is elevated in skin wound biopsies, which peaks at days 3-7 post-injury. ${ }^{10}$ To establish a causal relationship between TAK1 and ROS production profile in wound healing, we stained wound biopsies with the fluorescent dye CM-H2DCFDA (DCF). The staining revealed that the wound epithelia were a major site of ROS production that peaked at 3-7 days post-injury, coincident with elevated expression of TAK1 (Figures $1 \mathrm{a}$ and $\mathrm{b}$ ). DCF staining in the presence of an antioxidant $\mathrm{N}$-acetyl-cysteine (NAC) was completely abolished, indicating that the fluorescence signal was specific (Supplementary Figure 1).

To further examine the role of TAK1 in ROS production during wound healing, we constructed and examined organotypic skin co-cultures (OTCs) using either control ( $\left.\mathrm{K}_{\mathrm{CTRL}}\right)$ or TAK1-knockdown human keratinocytes $\left(\mathrm{K}_{\mathrm{TAK} 1}\right)$ with underlying human primary dermal fibroblasts. Our previous work has shown that this knockdown is specific and can be rescued by transfection with TAK1 cDNA. ${ }^{10}$ The overall epidermal thickness between $\mathrm{K}_{\mathrm{CTRL}}$ and $\mathrm{K}_{\mathrm{TAK} 1}$ OTCs was similar, but the suprabasal layer of the $\mathrm{K}_{\mathrm{TAK} 1}$ epidermis was significantly thinner when compared with $\mathrm{K}_{\mathrm{CTRL}}$ OTC, as evidenced by immunofluorescence staining for involucrin, a marker of keratinocyte terminal differentiation expressed only in the suprabasal layers of epidermis (Figure 1c). ${ }^{16}$ Notably, ROS production was elevated in the $\mathrm{K}_{\mathrm{TAK} 1}$-derived epithelia, as revealed by DCF staining (Figure 1c). Persistently elevated ROS within the normal cells leads to cellular apoptosis. Indeed, $\mathrm{K}_{\mathrm{TAK} 1}$ OTCs showed more TUNEL-positive apoptotic cells rather than $\mathrm{K}_{\mathrm{CTRL}}$ OTCs $(32.6 \pm 3.5$ versus $12.7 \pm 4.1$ TUNEL-positive cells per microscopic field, respectively; Figure 1c). This was further confirmed by immunodetection of cleaved caspase-3, an apoptotic marker (Figure 1d). As expected, the phosphorylation of JNK, a downstream target of TAK1, was reduced in $\mathrm{K}_{\mathrm{TAK} 1}$ OTCs compared with $\mathrm{K}_{\mathrm{CTRL}}$ OTCs (Figure 1d). Taken together, these observations suggest that TAK1 has a homeostatic role in modulating ROS level in keratinocytes during wound healing.

TAK1 confers anti-apoptotic properties in a cell-autonomous manner. Our above analysis revealed an increased number of apoptotic keratinocytes in $\mathrm{K}_{\mathrm{TAK} 1}$ epidermis. To investigate whether this observation was an autocrine or paracrine event, we examined cellular apoptosis in OTCs constructed using either $\mathrm{K}_{\mathrm{CTRL}}$ or $\mathrm{K}_{\mathrm{TAK} 1}$ with collagen, that is, absence of underlying fibroblasts, denoted $\mathrm{K}_{\mathrm{CTRL}} / \mathrm{Col}$ and $\mathrm{K}_{\mathrm{TAK} 1} / \mathrm{Col}$, respectively. $\mathrm{K}_{\mathrm{TAK} 1} / \mathrm{Col} \mathrm{OTCs}$ showed a stronger DCF fluorescence signal than $\mathrm{K}_{\mathrm{CTRL}} / \mathrm{Col}$ (Figure 1e). Similar to $\mathrm{K}_{\mathrm{TAK} 1}$ OTCs constructed with fibroblasts (Figure 1c), higher number of apoptotic cells were observed in $\mathrm{K}_{\mathrm{TAK}_{1}} / \mathrm{Col}$ when compared with $\mathrm{K}_{\mathrm{CTRL}} / \mathrm{Col}$ $(45.3 \pm 5.2$ versus $17.9 \pm 2.3$ versus TUNEL-positive cells per microscopic field, respectively; Figure 1e). This was corroborated by immunoblot analysis using cleaved caspase3 (Figure 1f). Resistance to anoikis and to TNF- $\alpha$-induced apoptosis are needed during epidermal stratification and in response to inflammation during wound healing, respectively. ${ }^{17}$ Thus, we subjected $\mathrm{K}_{\mathrm{CTRL}}$ and $\mathrm{K}_{\mathrm{TAK} 1}$ to either anoikis or TNF- $\alpha$ treatment and examined ROS levels and apoptosis by FACS. DCF labeling revealed increases in ROS production of more than 35 and $55 \%$ upon anoikis and TNF- $\alpha$ treatment, respectively (Figure 2a). This increased intracellular oxidative state was associated with $\sim 50 \%$ more apoptotic $\mathrm{K}_{\mathrm{TAK} 1}$ cells compared with $\mathrm{K}_{\mathrm{CTRL}}$ under both challenges, as determined by Annexin $\mathrm{V}$ staining (Figure 2b). Importantly, the co-treatment with NAC significantly reduced the apoptotic index in $\mathrm{K}_{\text {TAK1 }}$ (Figure 2b). Similarly, $\mathrm{K}_{\mathrm{TAK} 1}$-derived OTCs treated with NAC showed reduced TUNEL-positive apoptotic epidermal cells, reaching a number that was comparable to $\mathrm{K}_{\mathrm{CTRL}^{-}}$ derived OTCs (Figure 2c). No significant difference was observed in mean DCF signals and apoptotic index between untreated $\mathrm{K}_{\mathrm{CTRL}}$ and $\mathrm{K}_{\mathrm{TAK} 1}$ (Figures $2 \mathrm{a}$ and $\mathrm{b}$ ). Altogether, these results point towards a role for TAK1 in modulating ROS production and protecting keratinocytes against apoptosis via an autocrine, cell-autonomous manner.

TAK1 modulates the SCF/C-Kit/PKB $\alpha$ cascade. Our above findings showed that TAK1-deficient keratinocytes were hypersensitive to TNF- $\alpha$-induced apoptosis associated with elevated ROS production and that the anti-apoptotic effect of TAK1 was cell-autonomous. To understand the underlying mechanism for this TAK1 action, an unbiased proteomic analysis was done to screen for candidate growth factors and 
phosphoproteins. A growth factor array approach was used, conducting subtractive comparison of medium from OTCs constructed using either $\mathrm{K}_{\mathrm{TAK} 1}$ or $\mathrm{K}_{\mathrm{CTRL}}$ with collagen, that is, absence of underlying fibroblasts. A total of 41 growth factors were screened, and the results revealed a significant change only in the protein expression level of SCF. This was further confirmed by enzyme-linked immunosorbent assay (ELISA) on the OTC culture medium (Figure $3 a$ ), whereas no detectable change was observed for PDGF-AA. The expression of PDGF$A A$, which showed no difference between $\mathrm{K}_{\mathrm{TAK} 1^{-}}$and $\mathrm{K}_{\mathrm{CTRL}}$ derived OTC culture medium, served as control. Real-time $\mathrm{PCR}$ analysis of the $\mathrm{K}_{\mathrm{TAK} 1^{-}}$and $\mathrm{K}_{\mathrm{CTRL}}$-derived epidermis from OTCs showed corresponding changes at the mRNA level (Figure $3 b$ ). Furthermore, the re-introduction of an expression vector harboring TAK1 CDNA that has a silent third-codon point mutation within the siRNA target region restored the expression of SCF (Figure 3c). SCF binds and phosphorylates, that is, activates, its cognate receptor c-Kit. ${ }^{18}$ Corroborating our above finding, immunodetection indicated that the expression of phosphorylated $\mathrm{c}$-Kit was downregulated in $\mathrm{K}_{\mathrm{TAK} 1}$-derived epidermis, while total c-Kit protein remained unchanged (Figure 3d). The activation of $c-K i t$ has been shown to trigger the phosphoinositide-3 kinase (PI3K)/protein kinase $B(P K B) \alpha$ pro-survival pathway. ${ }^{19}$ Indeed, immunoblot showed that the expression of phosphorylated $\mathrm{PKB} \alpha$ and its downstream targets, like glycogen synthase kinase (GSK)-3 $\beta$, were reduced in $\mathrm{K}_{\text {TAK1 } 1}$ compared with $\mathrm{K}_{\mathrm{CTRL}}$ (Figure $3 \mathrm{~d}$ ). The expression level of total $\mathrm{PKB} \alpha$ remained unchanged (Figure 3d). Increased activity of $\mathrm{PKB} \alpha$, that is, higher phosphorylation, protects keratinocytes from apoptosis. ${ }^{17,20}$

To further investigate the importance of SCF/c-Kit/PKB $\alpha$, we cultured $\mathrm{K}_{\mathrm{CTRL}}$ and $\mathrm{K}_{\mathrm{TAK} 1} \mathrm{OTCs}$ in medium supplemented with recombinant SCF. We hypothesized that the increased apoptosis observed in $\mathrm{K}_{\mathrm{TAK} 1}$ could be rescued by exogenous SCF. Indeed, the addition of recombinant SCF lowered the number of TUNEL-positive apoptotic $\mathrm{K}_{\mathrm{CTRL}}$ and $\mathrm{K}_{\mathrm{TAK} 1} \mathrm{OTCs}$ compared with vehicle-treated OTCs (Figure $3 \mathrm{e}$ ). Although SCF treatment appeared to induce a trend towards more Ki67-positive proliferating cells, this effect on proliferation was not significant (Figure $3 e$ ). This was also confirmed by immunodetection using anti-caspase-3 and anti-PCNA antibodies (Figure $3 f$ ). We have previously shown that epidermal TAK1 modulates a double paracrine PDGF/HGF signaling to regulate keratinocyte proliferation that is required for proper wound healing. ${ }^{10}$ Specifically, $\mathrm{K}_{\mathrm{TAK} 1}$-derived epidermis showed increased proliferation when compared with
$\mathrm{K}_{\mathrm{CTRL}}$-derived epidermis as a result of the paracrine induction of dermal fibroblasts by keratinocyte-secreted PDGF-B. To rule out the probable influences exerted by this paracrine PDGF-mediated pathway, anti-PDGF antibodies were added as a control. $\mathrm{K}_{\mathrm{TAK} 1}$ OTCs treated with anti-PDGF antibody showed reduced epidermal proliferation (PCNA), but it has no effect on apoptosis (cleaved caspase-3) (Figure 3f). In contrast, the treatment with recombinant SCF reduced the number of apoptotic keratinocytes (Figures $3 e$ and f). Importantly, it underscored the distinct anti-apoptotic role of TAK1-mediated SCF expression. Altogether, these results indicate that SCF/C-Kit/PKB $\alpha$-mediated autocrine signaling has a pivotal role in the action of TAK1 in cell survival.

\section{The human SCF gene is a direct target of TAK1/JNK/ c-Jun signaling in keratinocytes. Our above results} showed that the absence of TAK1 increased apoptosis due to diminished SCF expression and thus $\mathrm{PKB} \alpha$ activation. However, the precise mechanism by which TAK1 regulates SCF level was still unclear. We first examined the expression of SCF mRNA and protein levels in $\mathrm{K}_{\mathrm{CTRL}}$ treated with TNF- $\alpha$ in the presence of various kinase inhibitors. With the exception of the specific JNK inhibitor 1,9-pyrazoloanthrone, all other inhibitors did not attenuate TNF- $\alpha$-induced increase in SCF mRNA and protein compared with vehicle-treated $\mathrm{K}_{\mathrm{CTRL}}$, as determined by quantitative PCR (qPCR) and ELISA, respectively (Figures $3 g$ and $h$ ). Next we studied the roles of different kinases in regulating the promoter of the human SCF gene. The human SCF promoter was isolated by PCR, and a proximal 853-bp fragment containing the transcription start site was subcloned into a luciferase reporter gene. ${ }^{21}$ This SCF promoter reporter construct was co-transfected with expression vectors encoding constitutively active (ca) kinases into $\mathrm{K}_{\mathrm{CTRL}}$. The activation of TAK1 stimulates the activity of downstream mediators, including $\mathrm{IKK} \alpha / \beta$, MKK7 and $\mathrm{JNK}^{9}$ Transient transfection studies showed that TAK1, MKK7 and JNK stimulated SCF promoter activity (Figure 3i), with no effect from IKK, PKA, MEK1, MEKK1 or SEK1. JNK activates transcription factor C-Jun, an obligate partner of AP-1. Previous in silico analysis of the human SCF promoter has identified a putative AP-1-binding site. ${ }^{21}$ Site-directed mutagenesis of the putative AP-1 binding site in the SCF promoter abolished the stimulating effect of TAK1, MKK7 and JNK (Figure 3i). A dominantnegative c-Jun (TAM67) blocks AP-1 activation by dimerizing with Jun or Fos family proteins. Transfection of an expression

\footnotetext{
Figure 1 ROS levels and cellular apoptosis are elevated in TAK1-deficient keratinocytes (K TAK1 $_{1}$ ). (a) Hematoxylin and eosin (H\&E) (left panel) and dichlorodihydrofluorescein diacetate (DCF) staining of ROS (right panel) in murine skin wound biopsies at the indicated days post-wounding. Scale bar $=40 \mu \mathrm{m}$. Dotted white line represents epidermal-dermal junction. Representative pictures of centrally dissected wound sections are shown. (b) Relative DCF signal intensity in murine skin wound biopsies at indicated days post-wounding. Values (mean \pm S.D.; $n=5$ ) represent mean fold changes in DCF signal intensity compared with the signal from Day 1 wound biopsies, as determined using ZEN 2009 (Carl Zeiss) software. (c) H\&E staining (first top panel), anti-involucrin immunofluorescence (second panel), DCF staining (third panel) and TUNEL analysis (bottom panel) of control ( $\mathrm{K}_{\mathrm{CTRL}}$ )- and $\mathrm{K}_{\text {TAK1 }}$-derived OTC sections. OTCs were constructed using either control (K $\mathrm{K}_{\mathrm{CTRL}}$ ) or TAK1-knockdown human keratinocytes $\left(\mathrm{K}_{\text {TAK1 }}\right)$ with underlying human primary fibroblasts $(\mathrm{F})$ and harvested after 2 weeks. Sections used for involucrin staining and TUNEL assay were counterstained with DAPI for nuclei (blue). Scale bar $=40 \mu \mathrm{m}$. Dotted white line represents epidermis-dermal junction. (d) Immunodetection of JNK, phosphorylated JNK ( $p(T 183) J N K)$, intact and cleaved caspase-3 in $\mathrm{K}_{\mathrm{CTRL}}$ and $\mathrm{K}_{\text {TAK1 }}$ epithelial tissues from corresponding OTCs, constructed with underlying fibroblasts. $\beta$-Tubulin was used as a loading and transfer control. (e) TAK1 confers anti-apoptotic properties in a cell-autonomous manner. H\&E staining (first panel), DCF staining (second panel), and in situ TUNEL analysis (bottom panel) of $\mathrm{K}_{\mathrm{CTRL}}$ and $\mathrm{K}_{\text {TAK } 1}$ OTC. OTCs were constructed on an underlying fibroblast-free collagen layer (Col). Sections were counterstained with DAPI for nuclei (blue). Scale bar $=40 \mu \mathrm{m}$. Dotted white line represents epidermal-dermal junction. Representative pictures of centrally dissected OTC sections are shown. (f) Immunoblot analysis of cleaved caspase- 3 in $\mathrm{K}_{\mathrm{CTRL}}$ and $\mathrm{K}_{\mathrm{TAK} 1}$ epidermis from corresponding OTCs constructed with underlying collagen. $\beta$-Tubulin was used as a loading and transfer control
} 
vector containing TAM67 induced a reduction in SCF mRNA expression in a dose-dependent manner, as determined by qPCR (Figure 3j), suggesting that human SCF is a direct target of c-Jun. To further determine if human SCF gene is a direct target gene of c-Jun, we performed an electrophoretic mobility shift assay (EMSA) and chromatin immunoprecipitation (ChIP). Specific proteinDNA complexes were detected by EMSA for the SCF AP1-binding site, which was effectively competed by unlabeled consensus AP-1 site (specific competitor, SC), but not by a non-specific competitor (NSC) oligonucleotide (Figure 3k). Mutation to the SCF AP-1-binding sequence (SCF mAP-1)
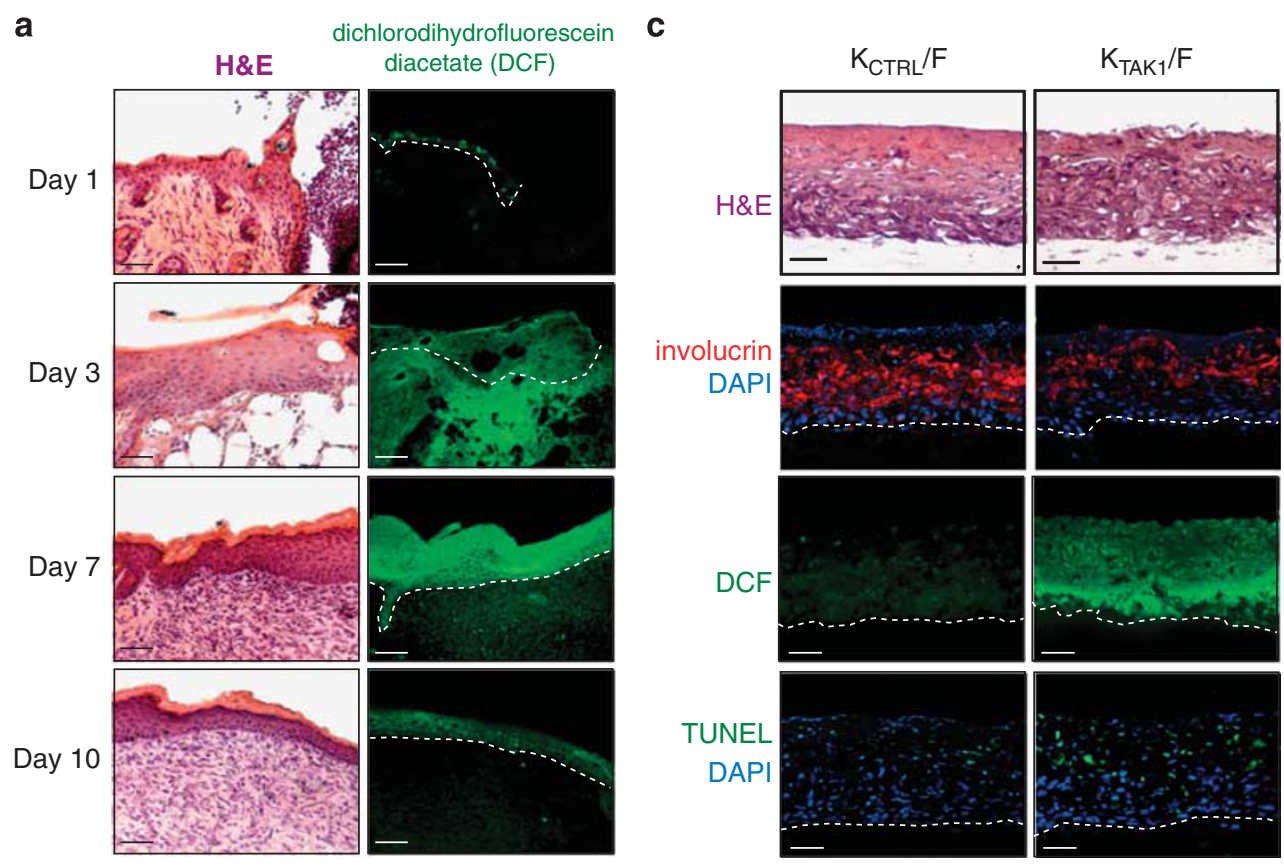

b

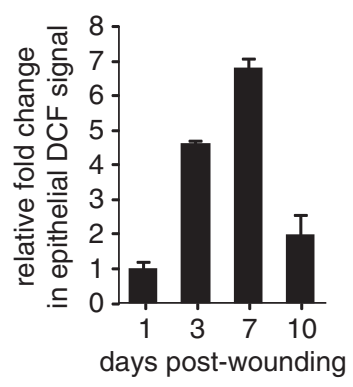

d

fibroblasts

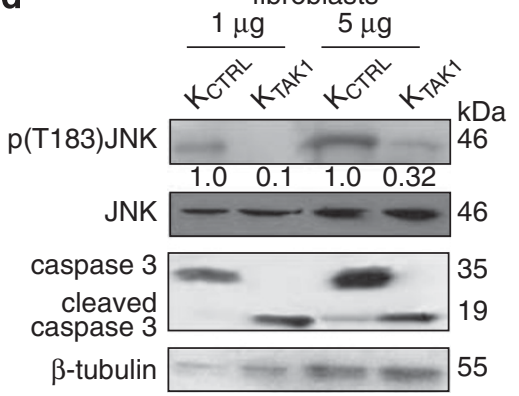

e

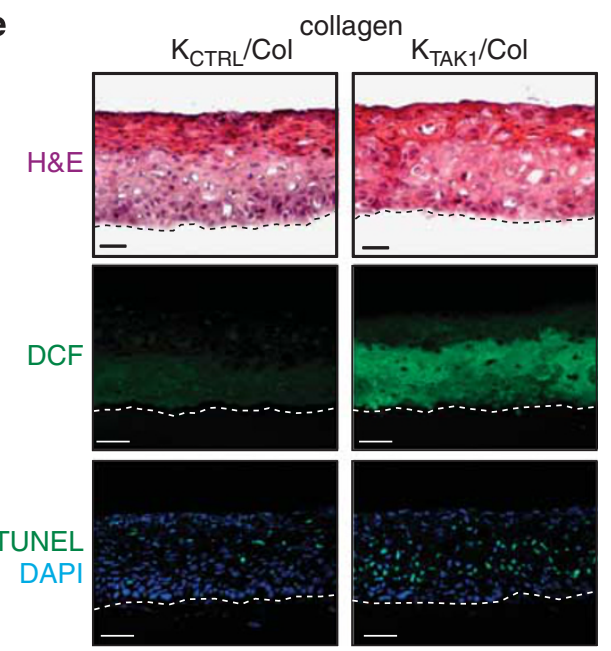

f

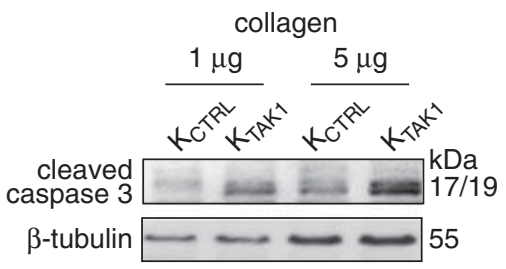


a

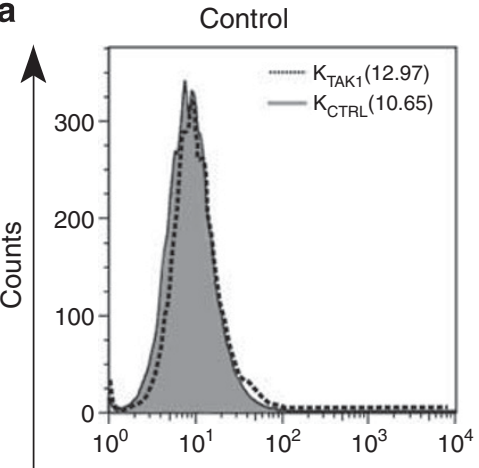

Anoikis

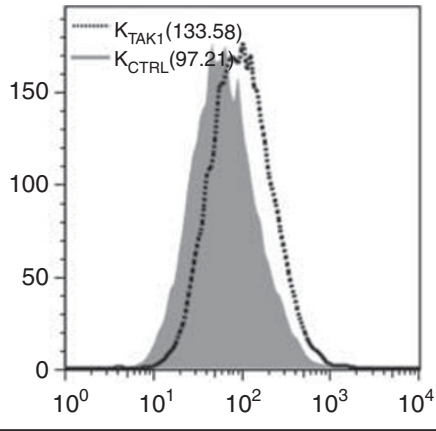

TNF- $\alpha(10 \mathrm{ng} / \mathrm{ml})$

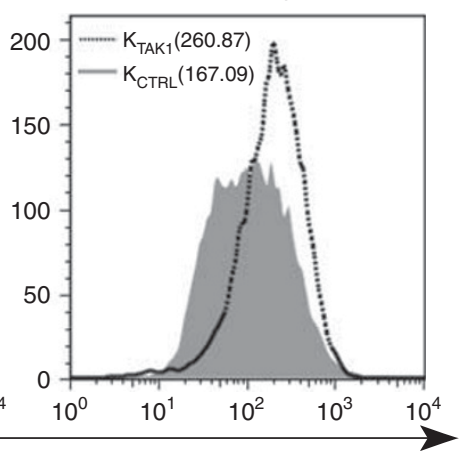

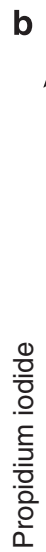

b
음
음
공
흥
음

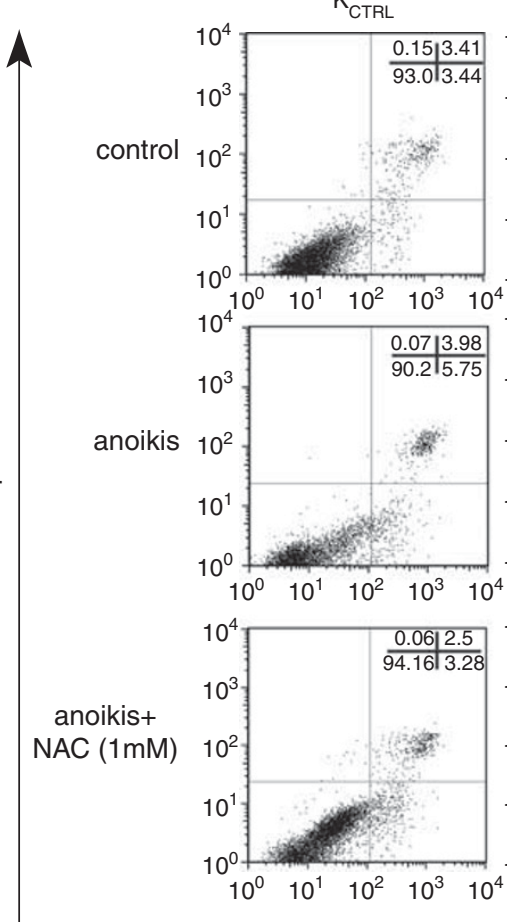

$\mathrm{K}_{\mathrm{TAK} 1}$
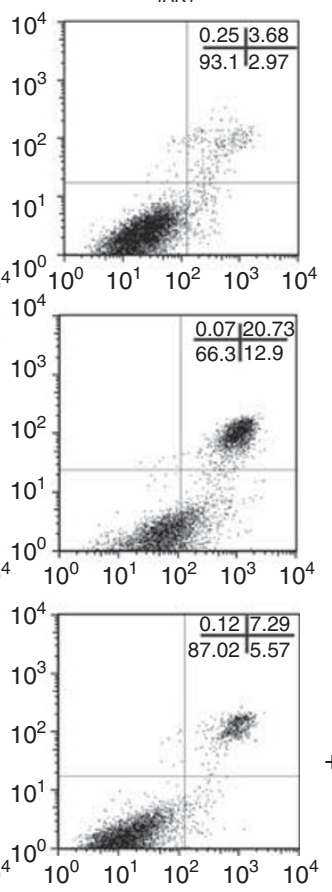

$\mathrm{K}_{\mathrm{CTRL}}$
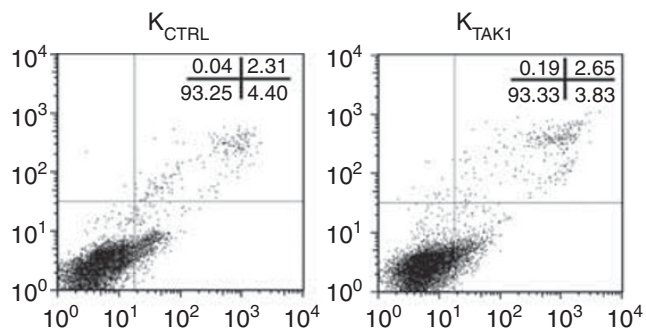

TNF- $\alpha$

(20 ng/ml)
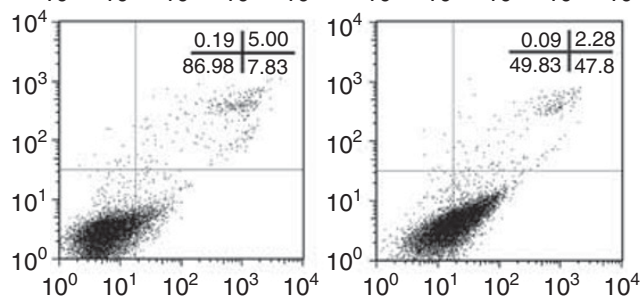

TNF- $\alpha$

$(20 \mathrm{ng} / \mathrm{ml})$ $+\mathrm{NAC}(1 \mathrm{mM})$
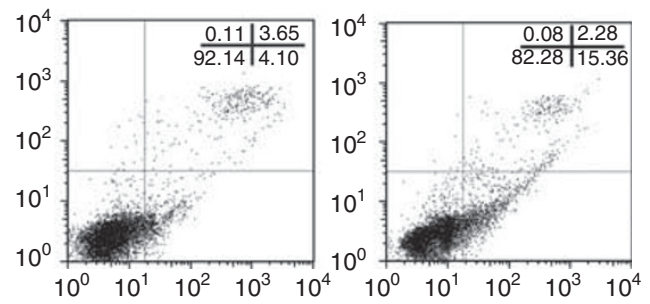

Annexin V FITC

C

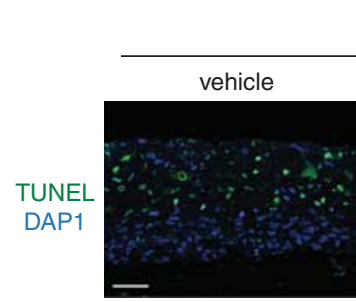

$\mathrm{K}_{\text {TAK } 1 / F}$

$0.1 \mathrm{mM} \mathrm{NAC}$

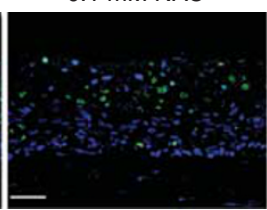

$1 \mathrm{mM} \mathrm{NAC}$

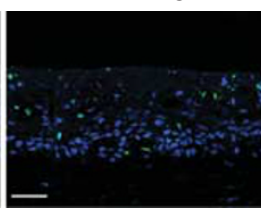

$\mathrm{K}_{\mathrm{CTRL}} / \mathrm{F}$

vehicle

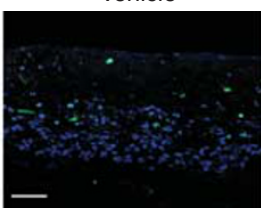

Figure 2 TAK1 deficiency increased ROS accumulation. (a) Representative FACS-derived histograms showing increased ROS in TAK1-knockdown (KAK1) compared with control human keratinocytes ( $\mathrm{K}_{\mathrm{CTRL}}$ ) during anoikis or TNF- $\alpha$ treatment. FACS analysis of $\mathrm{K}_{\text {TAK } 1}$ and $\mathrm{K}_{\mathrm{CTRL}}$ stained with DCF (10 000 events). No difference was observed with untreated control cells. Mean fluorescence intensities, indicated in brackets, were obtained from five independent experiments. Data were analyzed using CellQuest software (Becton Dickinson). The analyzer threshold was adjusted on the flow cytometer channel to exclude most of the subcellular debris to reduce the background noise using non-DCF stained cells. (b) Percentage of apoptotic $\mathrm{K}_{\mathrm{CTRL}}$ and $\mathrm{K}_{\mathrm{TAK} 1}$ after anoikis or TNF- $\alpha$ treatment, in the presence either vehicle or $1 \mathrm{mM}$ of NAC, as analyzed by FACS (10000 events). The sum of Annexin $\mathrm{V}^{+} / \mathrm{PI}^{-}$(early apoptosis) and Annexin $\mathrm{V}^{+} / \mathrm{PI}^{+}$cells (late apoptosis) were considered apoptotic. Values (mean \pm S.D., bold) denote apoptotic cells (\%) from five independent experiments. (c) TUNEL analysis of $\mathrm{K}_{\mathrm{CTRL}}$ - and $\mathrm{K}_{\text {TAK1 }}$-derived OTC sections. OTCs were constructed using either $\mathrm{K}_{\mathrm{CTRL}}$ or $\mathrm{K}_{\text {TAK } 1}$ with underlying human primary fibroblasts $(\mathrm{F})$, cultured in the presence of either vehicle or $1 \mathrm{mM} \mathrm{NAC}$ and harvested after 2 weeks. Sections used for TUNEL assay were counterstained with DAPI for nuclei (blue). Scale bar $=40 \mu \mathrm{m}$. Dotted white line represents epidermal-dermal junction 
eliminated its interaction with $\mathrm{K}_{\mathrm{CTRL}}$ nuclear extract. As positive control, the labeled consensus AP-1 (conAP-1) oligonucleotide was used as a probe, which was specifically competed by the $\mathrm{SC}$ (Figure 3k). ChIP was performed on $\mathrm{K}_{\mathrm{CTRL}}$ and $\mathrm{K}_{\mathrm{TAK} 1}$ using c-Jun antibody. In $\mathrm{K}_{\mathrm{CTRL}}$, c-Jun bound to this AP-1 site, but it did not bind in $\mathrm{K}_{\mathrm{TAK} 1}$ cells (Figure 3l). Additionally, no immunoprecipitation was seen with pre-immune serum in $\mathrm{K}_{\mathrm{TAK} 1}$ cells, and no amplification was detected for a control sequence upstream of the AP-1 site in the promoter of SCF (Figure $3 \mathrm{l}$ ). Taken together, these results suggest that TAK1/ MKK7/JNK/C-Jun signaling is necessary for the induction of SCF expression in keratinocytes.

SCF stimulates PKB $\alpha$ to modulate ROS production and cellular apoptosis. The above data showed that SCF is a direct target gene of $\mathrm{c}$-Jun and that SCF binding to its receptor $c$-Kit subsequently stimulates $\mathrm{PKB} \alpha$ activation. This novel link between TAK1 and PKB $\alpha$ via SCF functioned in an autocrine manner to regulate cell survival. However, it remained unclear if this signaling cascade has a prominent role in ROS production and thus cellular apoptosis. To this end, we examined the effect of either neutralizing anti-SCF antibody, recombinant SCF or the PI3K inhibitor LY294002 on ROS production in $\mathrm{K}_{\mathrm{CTRL}}$ and $\mathrm{K}_{\mathrm{TAK} 1}$ during anoikis and TNF- $\alpha$ exposure. $\mathrm{K}_{\mathrm{CTRL}}$ incubated with LY294002 or neutralizing anti-SCF antibody produced more ROS upon anoikis treatment or TNF- $\alpha$ induction, as determined by DCF labeling followed by FACS analysis (Figures $4 a$ and b). More importantly, this elevated level of ROS led to a higher percentage of apoptotic cells (Figure 4c). $\mathrm{K}_{\mathrm{TAK} 1}$ treated with exogenous recombinant SCF showed diminished ROS level and reduced percentage of apoptotic cells compared with vehicle-treated $\mathrm{K}_{\mathrm{TAK} 1}$ (Figure $4 \mathrm{c}$ ). Next, we cultured $\mathrm{K}_{\mathrm{TAK} 1}$ and $\mathrm{K}_{\mathrm{CTRL}}$ OTCs in a serum-free medium supplemented with the above inhibitors. The inhibition of the SCF/c-Kit/PKB $\alpha$ pathway in $\mathrm{K}_{\mathrm{CTRL}}$ resulted in elevated ROS production and increased keratinocyte apoptosis reminiscent of $\mathrm{K}_{\mathrm{TAK} 1}$. The same phenotype in $\mathrm{K}_{\mathrm{TAK} 1}$ was likewise rescued by exogenous SCF (Figure 4e).

It has been reported that ROS accumulation activates JNK and enhances FLIP degradation, which might be responsible for the increased sensitivity to TNF- $\alpha$-induced apoptosis in TAK1-knockout murine keratinocytes. ${ }^{22,23}$ Thus, we examined the effect of exogenous SCF or NAC on FLIP degradation. As expected, the treatment with TNF- $\alpha$ resulted in a rapid degradation of FLIP in $\mathrm{K}_{\mathrm{TAK} 1}$ cells. Importantly, immunoblot analysis showed that the degradation of FLIP was diminished in the presence of either SCF or NAC, supporting a prosurvival role of TAK1-mediated SCF pathway revealed herein (Figure 4f). This was similarly observed for $\mathrm{K}_{\text {TAK1 }}$ cells subjected to anoikis (Figure 4f). Altogether our results show that keratinocyte TAK1-mediated SCF expression, which stimulates $\mathrm{PKB} \alpha$ activity, has a major role in modulating keratinocyte ROS level and apoptosis in an autocrine manner (Figure 4g).

\section{Discussion}

ROS are critical intermediates of cellular signaling pathways. Upon injury, inflammatory signals present at a wound site stimulate the transient production of ROS that operate through redox-sensitive signaling pathways and transcription factors to execute specific biological processes, aiding wound repair. However, the dysregulated production of ROS leading to persistently elevated levels is associated with cancer, diabetes, inflammatory diseases, ischemia-related diseases, and neurodegeneration and are commonly thought to contribute to human pathologies and aging. ${ }^{24-26}$ Thus, it is crucial that the production of ROS be tightly controlled. In this study, we show that keratinocyte-specific TAK1 protects keratinocytes from apoptosis induced by anoikis and TNF- $\alpha$ and is associated with the diminished ROS. This involves a novel cell-autonomous mechanism by which TAK1 mediates the expression of SCF to stimulate the activation of the antiapoptotic PIK3/PKB $\alpha$ pathway. Our study reveals a functional role for SCF in keratinocytes and identifies TAK1 as a novel player linking inflammation and ROS regulation in skin redox biology.

During normal wound healing, we have consistently observed that increased ROS production is closely associated with the expression of TAK1 in mouse skin wound biopsies. Using RNA interference and OTCs, we previously found that the suppression of TAK1 in human keratinocytes leads to higher ROS levels accompanied by increased susceptibility to anoikis and TNF- $\alpha$-induced apoptosis, suggesting that TAK1 has a homeostatic role in regulating ROS generation in skin. Lending support to this hypothesis, keratinocyte-specific deletion of TAK1 hypersensitizes mouse keratinocytes to TNF- $\alpha$-mediated apoptosis via an elevated ROS, leading to massive cell death and chronic skin inflammation. A c-Jundependent mechanism was reported to inhibit excessive ROS production and salvage TAK1-deficient keratinocytes from the apoptotic fate, but the precise underlying mechanism still remains obscure. ${ }^{15}$ Recently, TNF-related apoptosisinducing ligand (TRAIL) was shown to induce ROS accumulation, enhance the activation of caspase- 3 and increase apoptosis in TAK1-null mouse keratinocytes. ${ }^{27}$ Further work showed that TAK1-mediated prevention of TRAIL-induced cell death was mediated by a non-NF- $\kappa \mathrm{B}$ mechanism. The role of SCF/C-Kit has been well documented in promoting survival, proliferation and differentiation in bone marrowderived hematopoietic cells. ${ }^{28}$ In the human skin, SCF/c-Kit signaling has a pivotal role in the process of melanogenesis. Although the expression of SCF and its receptor c-Kit has been reported in keratinocytes, ${ }^{29-31}$ its homotypic role in keratinocyte biology remains elusive. We showed that TAK1/ $\mathrm{MKK} 7 / \mathrm{JNK} / \mathrm{c}-\mathrm{Jun}$ signaling in human keratinocytes results in the increased expression of SCF, which induces its receptor $\mathrm{c}-\mathrm{Kit}$ to reduce $\mathrm{ROS}$ production and activates a $\mathrm{PKB} \alpha$-dependent mechanism inhibiting TNF- $\alpha$-induced cell death and anoikis. This novel cell-autonomous mechanism clarifies and furthers our previous work, but importantly, it underscores the homeostatic role of TAK1 and SCF/c-Kit signaling in the regulation of ROS production and indicates their novel anti-apoptotic role in keratinocytes.

Prolonged inflammation that induces oxidative stress has been implicated in dermatological conditions like psoriasis. ${ }^{32}$ Our findings and those of others have shown that a deficiency in TAK1, and hence reduced c-Jun activity, results in a greater oxidative stress in keratinocytes. Our previous findings also 
show that TAK1-deficient keratinocytes have reduced NF- $\kappa \mathrm{B}$ activation and $\mathrm{pVHL}$ expression. ${ }^{10}$ Interestingly, analysis of skin biopsies from patients with psoriasis shows that $\mathrm{C}$-Jun and $\mathrm{pVHL}$ are downregulated in psoriatic skin. ${ }^{33,34}$ Furthermore, a mouse model of psoriasis is also deficient in epidermal Jun proteins. ${ }^{35}$ In view of these supporting evidence, it will be worth to examine the expression or activity of TAK1 in human psoriatic skin biopsies.

Wounds share many features with cancerous tumors. Studies have suggested that for reasons yet unknown, the genes active during wound healing are also activated in cancers with the worst outcomes. $^{36}$ Like wound healing, inflammation is a critical component of tumor progression. ${ }^{37}$ Many cancers arise from sites of infection, chronic irritation and inflammation. It is now becoming clear that in response to stress in the tumor microenvironment, such as inflammation, tumor cells exploit various signaling molecules to sustain and promote their growth, invasion and metastasis. ${ }^{37}$ Recent studies have shown that tumors utilize a redox-based mechanism to prevent death by anoikis. ${ }^{38}$ Anoikis resistance is an essential feature of cancer a
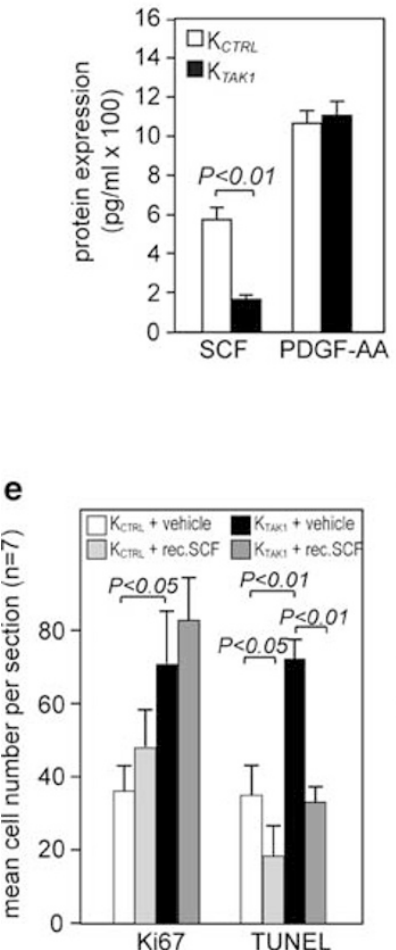

b

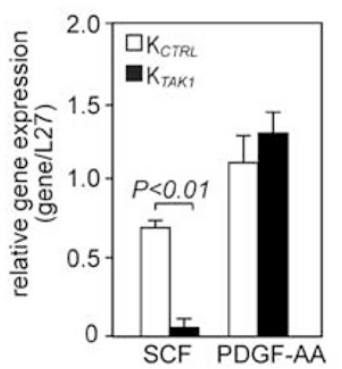

f

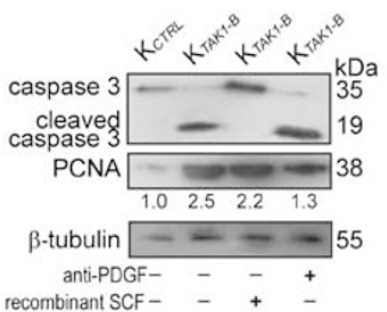

C

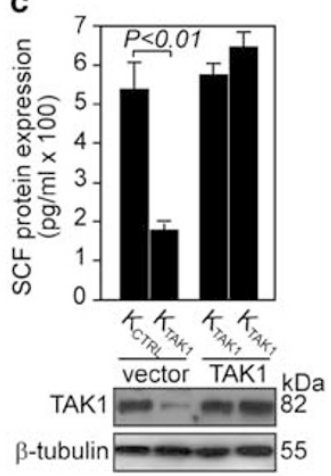

d

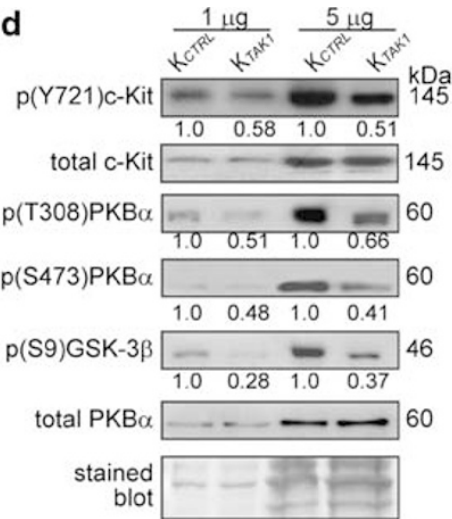

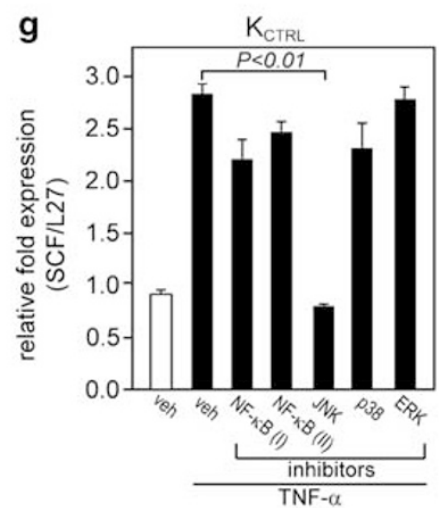
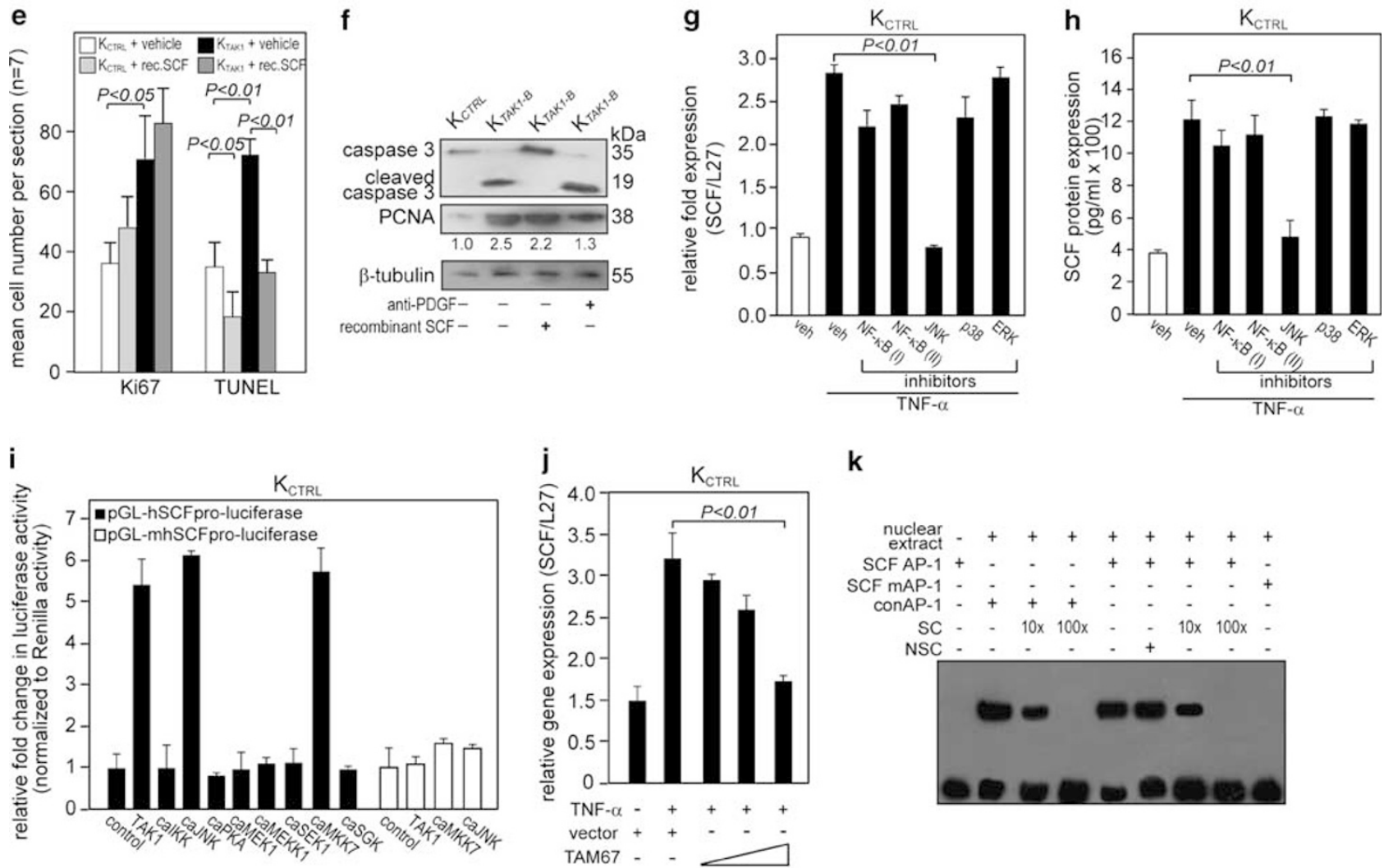

$\mathbf{k}$
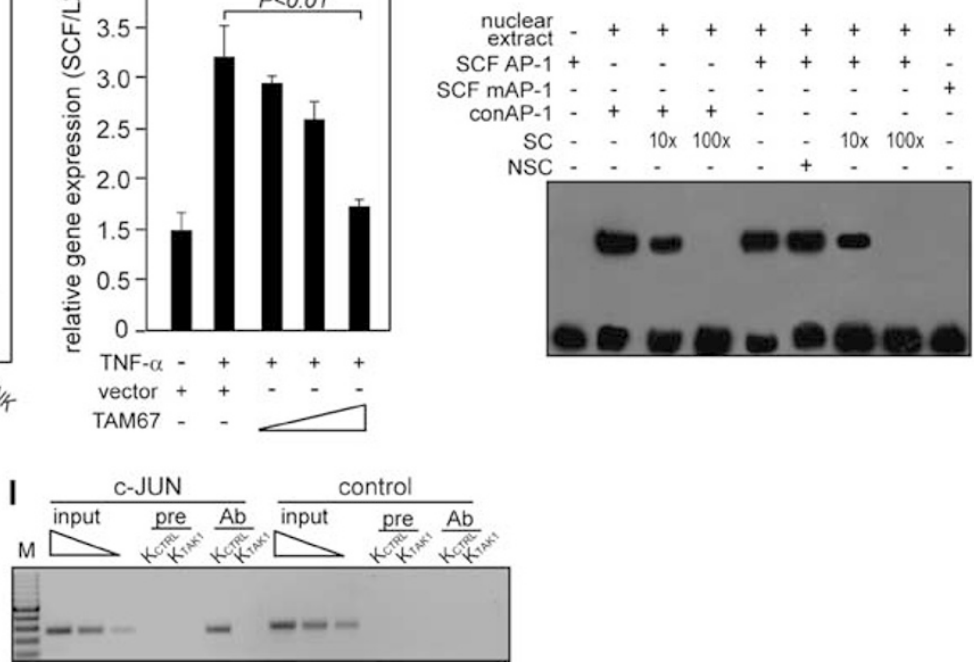
cells, yet its acquisition is a central problem in cancer biology. Although not investigated in this study, our findings suggest, at least in part, a role for TAK1-mediated SCF/c-Kit signaling that confers anoikis resistance as a possible tumor response to inflammation. Our study offers new insights into anti-inflammatory- and anti-redox-based approaches as viable cancer treatment strategies.

\section{Materials and Methods}

Reagents. Antibodies were purchased against TAK1 (Upstate Biotechnology, Waltham, MA, USA) for immunofluorescence and against TAK1, caspase-3, phospho(T183)-JNK, phospho(Y721)c-Kit, phospho(S473)PKB $\alpha$, p(S9)GSK-3 $\beta$, total JNK, c-FLIP, c-Kit (Cell Signaling, Danvers, MA, USA), involucrin (Novocastra, Newcastle upon Tyne, UK), $\beta$-tubulin, PCNA, phospho-c-Jun and secondary HRP. conjugated antibodies (Santa Cruz Biotechnology, Santa Cruz, CA, USA) for immunoblot. Neutralizing anti-SCF antibody and recombinant SCF were from Peprotech (Rocky Hill, NJ, USA). Collagen Type I rat tail was obtained from BD Biosciences (Bedford, MA, USA). Human primary fibroblasts, keratinocytes and corresponding culture medium were purchased from Cascade Biologics (Portland, OR, USA). Transfection reagent ExGen 500 was purchased from Fermentas (Vilnius, Lithuania). Double-promoter lentivirus-based siRNA vector and pFIV packaging kit were acquired from System Biosciences (Mountain View, CA, USA). All restriction enzymes and DNA/RNA-modifying enzymes were obtained from Fermentas. Kinase inhibitors were acquired from Merck (Darmstadt, Germany). PI3K inhibitor LY294002 was purchased from Cayman Chemical (Ann Arbor, MI, USA). Otherwise, chemicals were bought from Sigma-Aldrich (St. Louis, MO, USA).

Cell culture conditions and organotypic skin co-culture. Human dermal fibroblasts and keratinocytes were routinely cultured in a $37^{\circ} \mathrm{C}, 5 \% \mathrm{CO}_{2}$, humidified incubator. OTCs were performed as previously described. ${ }^{11}$ Briefly, a fibroblast density of $1 \times 10^{5} \mathrm{cell} / \mathrm{s} / \mathrm{ml}$ of collagen was used to reconstruct OTCs. The air-exposed process was performed in a $37^{\circ} \mathrm{C}$ incubator with $5 \% \mathrm{CO}_{2}$ and $70 \%$ humidity. The OTC was cultured for another 14 days, changing the medium every 2 days. Inhibitors, agonists and antagonists were added into the OTC medium. Serum-free OTC medium was composed of DMEM: Ham's F12 in $3: 1$ volume ratio, $1 \mathrm{mg} / \mathrm{ml}$ fatty acid free albumin, $10 \mu \mathrm{M}$ carnitine, $0.4 \mu \mathrm{g} / \mathrm{ml}$ hydrocortisone, $1 \mu \mathrm{M}$ isoproterenol, $1 \mu \mathrm{M} \alpha$-tocopherol, $5 \mu \mathrm{M}$ linoleic acid, $7 \mu \mathrm{M}$ arachidonic acid, $25 \mu \mathrm{M}$ oleic acid, $50 \mu \mathrm{g} / \mathrm{ml}$ ascorbic acid, $10 \mu \mathrm{M}$ serine, $100 \mathrm{nM}$ adenine, $100 \mathrm{nM}$ cholera toxin, $2 \mathrm{ng} / \mathrm{ml} \mathrm{epidermal} \mathrm{growth} \mathrm{factor} \mathrm{and} 2 \mathrm{ng} / \mathrm{ml} \mathrm{TGF}-\alpha$. OTCs were kept at $37^{\circ} \mathrm{C}$, $5 \% \mathrm{CO}_{2}$ with a relative humidity of $70 \%$

Lentivirus siRNA constructs and transduction. The sequences of TAK1 and control siRNA are shown in Supplementary Table 1. The siRNAs were cloned into the pFIV-HI/U6 siRNA vector according to the manufacturer's protocol (System Biosciences). Positive clones were identified by PCR and by DNA sequencing. Production of pseudoviral particles and transduction of cells were done as described by the manufacturer. Following transduction, the cells were enriched with $350 \mathrm{ng} / \mathrm{ml}$ puromycin for a week.

Total RNA isolation and real-time quantitative PCR. Total RNA was isolated from cells using a PureLink RNA kit (Invitrogen, Carlsbad, CA, USA) following the supplier's protocol. Total RNA $(2.5 \mu \mathrm{g})$ was reverse-transcribed with oligo-dT primers using RevertAid H Minus M-MuLV (Fermentas). Real-time PCR was performed with KAPA SYBR Fast qPCR (KAPABiosystem, Cape Town, South Africa). Melt curve analysis was included to assure that only one PCR product was formed. Expression was normalized to the control gene ribosomal L27, which did not change under any of the experimental conditions studied. The sequences of primers are shown in Supplementary Table 1.

Transient transfection and transactivation assay. TAK1 CDNA was subcloned into pCMV5 mammalian expression vector (Stratagene, Santa Clara, CA, USA). A 983-bp $(-853$ to +130$)$ promoter of the human SCF gene was PCRamplified from human genomic DNA using Pfu polymerase. ${ }^{21}$ The resulting fragment was subcloned into pGL-3 basic luciferase reporter vector (Promega, Madison, WI, USA). Site-directed mutagenesis of the AP-1-binding site at -573 was performed using QuikChange Site-Directed Mutagenesis kit (Stratagene). Primer sequences for PCR are given in Supplementary Table 1. Keratinocytes were co-transfected with a luciferase reporter driven by the SCF promoter construct, cDNAs encoding for various kinases and $\mathrm{pEF} 1-\beta$-galactosidase as a control for transfection efficiency. The caPKA, caMEK1 and caMEKK1 were obtained from Clontech (Mountain View, CA, USA). The caMKK7 was obtained from Cell BioLabs (San Diego, CA, USA). The various TAK1, caSEK1, caJNK, caSGK and calKK expression vectors were obtained from E Nishida (Kyoto University, Japan), RJ Davis (University of Massachusetts Medical School, Worcester, MA, USA), DJ Templeton (University of Virginia Medical School, Charlottesville, VA, USA) and DV Goeddel (Tularik, Inc., South San Francisco, CA, USA). After transfection, cells

Figure 3 TAK1 promotes cell survival through the SCF/c-Kit/PKB $\alpha$ pathway. (a and $\mathbf{b}$ ) Expression level of SCF (a) protein and (b) mRNA in human keratinocytes transduced with either control ( $\mathrm{K}_{\mathrm{CTRL}}$ ) or TAK1 siRNA $\left(\mathrm{K}_{\text {TAK1 } 1}\right)$. SCF protein levels were determined from culture medium of $\mathrm{K}_{\mathrm{CTRL}}$ and $\mathrm{K}_{\text {TAK1 }}$ by ELISA. Platelet-derived growth factor (PDGF)-AA levels were also measured as a control. Real-time qPCR revealed the relative gene expression of SCF and PDGF-AA in $\mathrm{K}_{\text {TAK1 }}$ and $\mathrm{K}_{\mathrm{CTRL}}$. Ribosomal L27 was used for normalization. Values (mean \pm S.D.) were from five independent experiments. (c) Expression levels of SCF (upper panel) and TAK1 (lower panel) proteins in $\mathrm{K}_{\mathrm{CTRL}}$ and $\mathrm{K}_{\mathrm{TAK} 1}$ transfected with either an empty vector or an expression vector encoding a TAK1 cDNA with a silent third-codon mutation in the siRNA targeting region (upper panel). Two independent transfections are shown. SCF and TAK1 proteins were measured by ELISA and immunoblot, respectively. $\beta$-Tubulin was used as a loading and transfer control. (d) Immunoblot analysis of total and phosphorylated c-Kit and its downstream mediators of the PI3K/PKB $\alpha$ pathway in $\mathrm{K}_{\text {CTRL }}$ and $\mathrm{K}_{\text {TAK }}$ epidermis from OTCs constructed with underlying collagen. The level of $p(Y 721) c-K i t$, the activated form of the SCF receptor, was measured in $\mathrm{K}_{\mathrm{CTRL}}$ and $\mathrm{K}_{\text {TAK1 }}$ epidermis. Total c-Kit, PKB $\alpha$ and Coomassie-stained blots were used as loading and transfer controls. (e) Quantification of Ki67 and TUNEL-positive $\mathrm{K}_{\text {CTRL }}$ and $\mathrm{K}_{\text {TAK } 1}$ in OTCs supplemented with either vehicle (PBS) as a control or recombinant SCF (rec. SCF). Mean numbers of proliferating and apoptotic cells were numerated after detection by anti-Ki67 antibody or TUNEL, respectively. Values are means from five standardized microscopic fields per section, performed on seven sections from three independent OTCs. (f) Immunodetection of cleaved caspase-3 (apoptotic marker) and PCNA (proliferation marker) in the epithelia from $\mathrm{K}_{\mathrm{CTRL}}$ - and $\mathrm{K}_{\text {TAK1 }}$-derived OTCs treated with either PBS (-), anti-PDGF antibody or recombinant SCF $(+)$. $\beta$-Tubulin served as a transfer and loading control. Values below each band represent the mean fold differences $(n=3)$ in expression level compared with $\mathrm{K}_{\mathrm{CTRL}}$, which was assigned the value of 1. ( $\mathbf{g}$ and $\mathbf{h}$ ) TAK1 regulates SCF expression via MKK7/JNK/c-Jun pathway. Expression level of SCF (g) mRNA and (h) protein in $\mathrm{K}_{\text {CTRL }}$ treated with either DMSO (vehicle control) or specific inhibitors of the indicated kinases in the presence of TNF- $\alpha(10 \mathrm{ng} / \mathrm{ml})$. The various kinase inhibitors were NF- $\kappa B$ (I): BAY 11-7082; NF- $\kappa B$ (II): SN50; JNK: 1,9-pyrazoloanthrone; p38: (2-(4-chlorophenyl)-4-(4-fluorophenyl)-5-pyridin-4-yl-1,2-dihydropyrazol-3-one); and ERK1/ 2: PD98059. Ribosomal L27 was used for normalization in qPCR. Protein levels were determined by ELISA. (i) Transactivation assay in keratinocytes co-transfected with a luciferase reporter gene driven by the human SCF promoter ( $\mathrm{pGL}$-hSCFpro-luciferase), cDNA encoding for indicated constitutively active (ca) kinases and pEF1- $\beta$ galactosidase as control for transfection efficiency. Luciferase activity was measured, and normalized reporter activity is shown as fold induction compared with reporter construct-transfected $\mathrm{K}_{\text {CTRL }}$ (control). The SCF promoter reporter construct with a mutated AP-1 site is denoted pGL-mSCFpro-luciferase. Values (mean \pm S.D.) are from three independent experiments. (j) Relative SCF mRNA expression in $\mathrm{K}_{\mathrm{CTRL}}$ transfected with increasing amount of dominant-negative c-Jun (TAM67). Ribosomal L27 was used for normalization. (k) EMSA of the human SCF AP-1-binding site. Biotin-labeled SCF AP-1 binding sequence was incubated with nuclear extract isolated from $\mathrm{K}_{\mathrm{CTRL}}$. NSC denotes non-specific competitor, a scrambled AP-1-binding sequence. SC denotes non-labeled consensus AP-1 sequence (conAP-1). As positive control, conAP-1 was used. Mutated SCF AP-1 site is denoted as SCF mAP-1. (I) Human SCF is a direct AP-1 target gene. Chromatin immunoprecipitation was done in $K_{C T R L}$ and $K_{\text {TAK } 1}$ using pre-immune $\operatorname{lgG}$ (pre) or antibody against phospho-c-Jun (Ab). The promoter region with the AP-1-binding site was immunoprecipitated and specifically amplified in $\mathrm{K}_{\mathrm{CTRL}}$ using $\mathrm{Ab}$. No amplified signal was obtained in $\mathrm{K}_{\mathrm{TAK} 1}$ or using pre-immune IgG (pre). A control region upstream of the AP-1-binding site served as a negative control. M: 100-bp DNA marker 
a
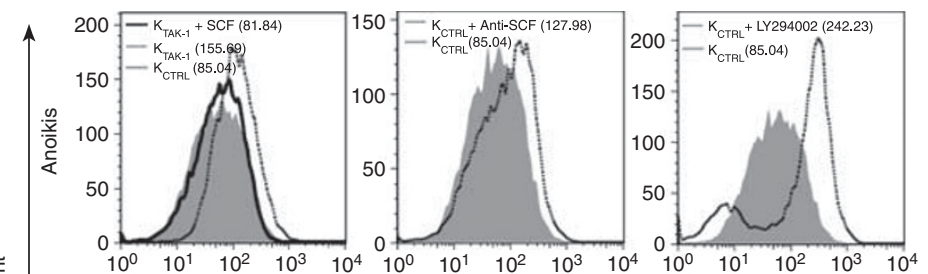

b
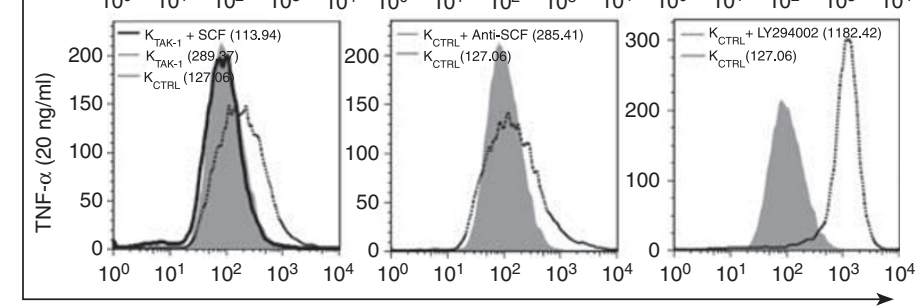

DCF (FITC)

C
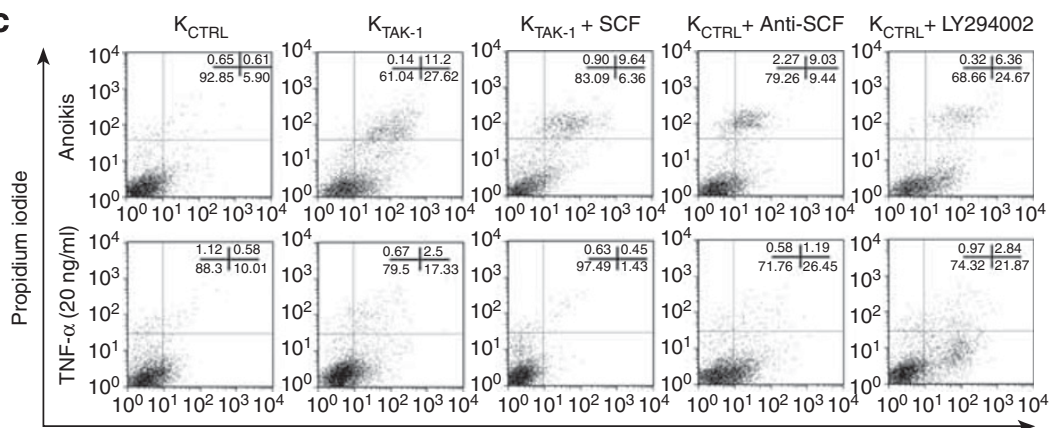

Annexin V FITC

\section{f}
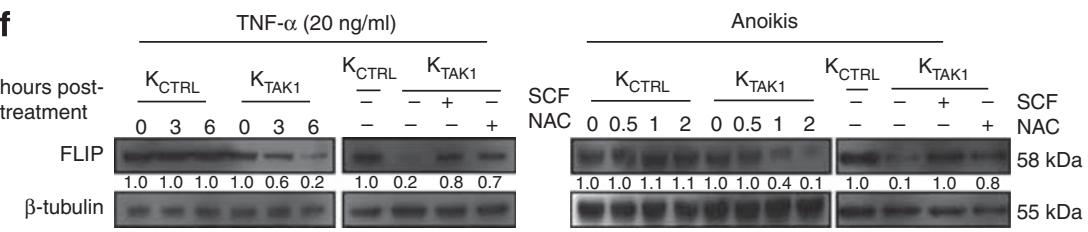

d

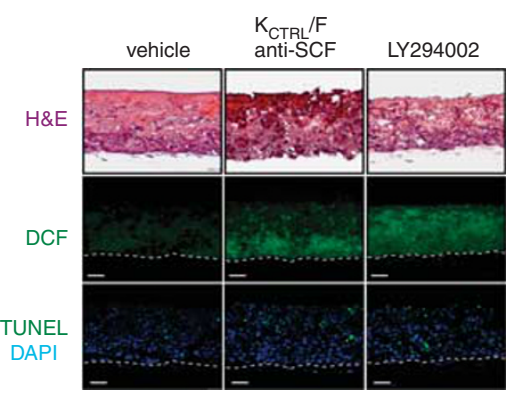

e

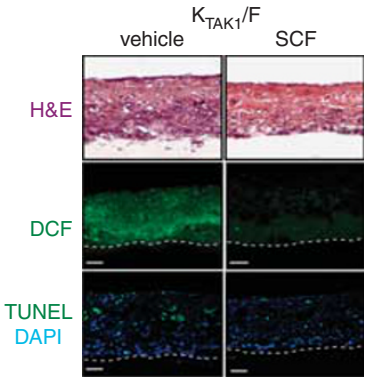

g

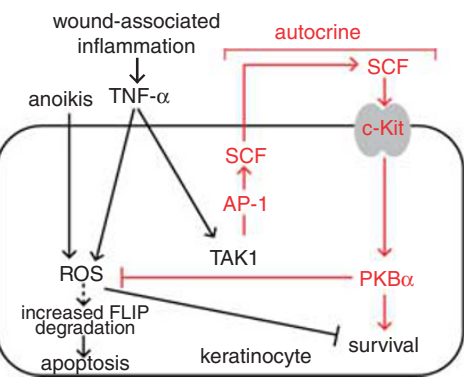

Figure 4 SCF stimulates $\mathrm{PI} / 3 \mathrm{~K} / \mathrm{PKB} \alpha$ signaling to modulate ROS production and cellular apoptosis. (a and $\mathbf{b})$ Representative FACS-derived histograms showing increased ROS level in $\mathrm{K}_{\text {TAK } 1}$ and $\mathrm{K}_{\mathrm{CTRL}}$ treated overnight with $25 \mu \mathrm{M}$ LY294002, $50 \mathrm{ng} / \mathrm{ml}$ recombinant SCF or $200 \mathrm{ng} / \mathrm{ml}$ neutralizing anti-SCF antibody, before DCF labeling and apoptosis induction by (a) anoikis or (b) TNF- $\alpha(10 \mathrm{ng} / \mathrm{ml})$ treatments. Mean fluorescence intensities, indicated in brackets, were obtained from five independent experiments. (c) Percentage of apoptotic $\mathrm{K}_{\mathrm{CTRL}}$ and $\mathrm{K}_{\mathrm{TAK} 1}$ treated as described in ( $\mathbf{a}$ and $\mathbf{b}$ ) and analyzed by FACS (10000 events). The totality of Annexin $\mathrm{V}^{+} / \mathrm{PI}^{-}$(early apoptosis) and Annexin $\mathrm{V}^{+} / \mathrm{PI}^{+}$cells (late apoptosis) were considered apoptotic. Values (mean \pm S.D., bold) denote apoptotic cells $(\%)$ from five independent experiments. (d and $\left.\mathbf{e}\right) \mathrm{DCF}$ staining of (d) $\mathrm{K}_{\mathrm{CTRL}}$ and (e) $\mathrm{K}_{\text {TAK1 }}$ OTCs constructed on an underlying fibroblast-embedded collagen matrix, cultured in the presence of either neutralizing anti-SCF antibody, the PI3K inhibitor LY294002 or exogenous recombinant SCF. H\&E staining (top panel) reveals tissue structure and morphology. In situ TUNEL staining (bottom panel) identifies apoptotic cells. Cells were counterstained with DAPI (blue) for nuclei. (f) Immunodetection of FLIP protein from TNF- $\alpha$ - and anoikis-treated $\mathrm{K}_{\mathrm{CTRL}}$ and $\mathrm{K}_{\text {TAK } 1}$ cells in the absence $(-)$ or presence $(+)$ of either $50 \mathrm{ng} / \mathrm{ml}$ of recombinant SCF or $1 \mathrm{mM}$ of NAC. $\beta$-Tubulin served as a transfer and loading control. Values below each band represent the mean fold differences $(n=3)$ in expression level compared with vehicle-treated or anoikis-treated $\mathrm{K}_{\mathrm{CTRL}}$, which was assigned the value of 1 . (g) TAK1 sustains keratinocyte survival by regulating ROS production. Epidermal TAK1 protects keratinocytes from ROS-mediated cell death by an autocrine mechanism through the release of SCF. Upon wounding, inflammatory signals, like TNF- $\alpha$, present at the wound site stimulate the production of ROS. Anoikis also induces ROS production, and anoikis resistance is essential for the survival of wound keratinocytes. Elevated ROS sensitize keratinocytes to TNF- $\alpha$-induced cell death and anoikis by increasing FLIP degradation. Our study showed that the simultaneous activation of TAK1 allows for tightly controlled ROS generation via the autocrine action of SCF (bold). TAK1 activates MKK7/JNK/cJun to stimulate the expression of SCF. c-Jun is an obligate partner of transcription factor AP-1. By binding to and activating its receptor c-Kit, SCF triggers the activation of $\mathrm{PI} 3 \mathrm{~K} / \mathrm{PKB} \alpha$ signaling to modulate ROS level and protect keratinocytes against ROS-mediated apoptosis. Thus, TAK1-deficient keratinocytes exhibit elevated ROS production and massive cellular apoptosis

were cultured for $48 \mathrm{~h}$ before lysis. Luciferase activity was measured using the Promega luciferase assay on a Microbeta Trilux (Perkin-Elmer, Waltham, MA, USA). $\beta$-Galactosidase activity was measured in the cell lysate by a standard assay using 2-nitrophenyl- $\beta \mathrm{D}$-galactopyranoside as a substrate. The expression vector containing dominant-negative AP-1 (TAM67) was transfected in increasing doses into $\mathrm{K}_{\text {CTRL, }}$, and the expression level of SCF mRNA was determined by qPCR.

Electrophoretic mobility shift assay. Non-radioactive EMSA was performed using a LightShift Chemiluminescent EMSA kit (Thermo Scientific,
Waltham, MA, USA). The AP-1 (-573)-binding site of the human SCF promoter was examined. $^{21}$

Protein array analysis and enzyme-linked immunosorbent assay. A growth factor array membrane was processed according to the manufacturer's protocol (RayBiotech, Norcross, GA, USA). Serum-free conditioned medium ( $1 \mathrm{ml}$ ) or $0.5 \mathrm{mg}$ cell lysate proteins was used. Protein spots were detected by chemiluminescence. Signal intensities were quantified using ImageJ analysis software (National Institutes of Health, Bethesda, MD, USA), and were normalized to the mean intensity of the positive controls on each membrane. The 
concentrations of growth factors were measured in culture supernatants using sandwich ELISA according to the manufacturer's instruction (R\&D Systems, Minnesota, MN, USA).

Immunofluorescence and TUNEL assay. Tissues were fixed with $4 \%$ paraformaldehyde in PBS for $2 \mathrm{~h}$ at room temperature, washed twice with PBS and embedded in Tissue-Tek OCT compound medium (Sakura, Leica, Minneapolis, MN, USA). Eight-micrometer cryosections were processed for immunofluorescence as described previously. ${ }^{11}$ Apoptotic cells were detected using the TUNEL assay according to the manufacturer's protocol (Roche, Mannheim, Germany). As positive control for the TUNEL assay, the section was pre-treated with DNase I. The slides were counterstained with DAPI and mounted for microscopic observation. Images were taken using an LSM510 META confocal laser scanning microscope with a Plan-Apochromat $\times 63 / 1.40$ oil objective and ZEN 2008 software (Carl Zeiss, Singapore, Singapore).

Chromatin immunoprecipitation. In vivo ChIP was carried out as previously described, except anti-phospho-c-Jun antibody was used. ${ }^{39}$ The putative AP-1-binding site in the human SCF promoter was previously described. ${ }^{21}$ Primers used for ChIP are given in Supplementary Table 1.

Apoptosis treatments, ROS measurement and FACS analysis. Keratinocytes were subjected to anoikis treatment as previously described. ${ }^{20}$ Keratinocytes in serum-free medium were treated with $10 \mathrm{ng} / \mathrm{ml}$ TNF- $\alpha$ to induce apoptosis. Treated keratinocytes were incubated with $10 \mu \mathrm{M}$ CM-H2DCFDA (Invitrogen) for $30 \mathrm{~min}$ at $37^{\circ} \mathrm{C}$, harvested and analyzed by flow cytometry (LSR II from BD Biosciences). Apoptotic cells were detected using an Annexin V/propidium iodide staining kit (BD Biosciences) according to the manufacturer's protocol. For indicated experiments, cells were treated with either vehicle, $25 \mu \mathrm{M} \mathrm{LY} 294002,200 \mathrm{ng} / \mathrm{ml}$ anti-SCF antibody, $50 \mathrm{ng} / \mathrm{ml} \mathrm{SCF}$ or $1 \mathrm{mM} \mathrm{NAC}$

\section{Conflict of interest}

The authors declare no conflict of interest.

Acknowledgements. This work was supported by grants from Ministry of Education, Singapore (ARC 8/06) and Nanyang Technological University, Singapore (RGD 127/05, 158/06).

1. Albanesi C, Pastore S. Pathobiology of chronic inflammatory skin diseases: interplay between keratinocytes and immune cells as a target for anti-inflammatory drugs. Curr Drug Metab 2010; 11: 210-227.

2. Pierce GF. Inflammation in nonhealing diabetic wounds: the space-time continuum does matter. Am J Pathol 2001; 159: 399-403.

3. Circu ML, Aw TY. Reactive oxygen species, cellular redox systems, apoptosis. Free Radic Biol Med 2010; 48: 749-762.

4. Roy S, Khanna S, Nallu K, Hunt TK, Sen CK. Dermal wound healing is subject to redox control. Mol Ther 2006; 13: 211-220.

5. D'Autréaux B, Toledano MB. ROS as signalling molecules: mechanisms that generate specificity in ROS homeostasis. Nat Rev Mol Cell Biol 2007; 8: 813-824.

6. Novo E, Parola M. Redox mechanisms in hepatic chronic wound healing and fibrogenesis Fibrogenesis Tissue Repair 2008; 1: 5.

7. Omori E, Matsumoto K, Sanjo H, Sato S, Akira S, Smart RC et al. TAK1 is a master regulator of epidermal homeostasis involving skin inflammation and apoptosis. J Biol Chem 2006; 281: 19610-19617.

8. Sato S, Sanjo H, Takeda K, Ninomiya-Tsuji J, Yamamoto M, Kawai T et al. Essentia function for the kinase TAK1 in innate and adaptive immune responses. Nat Immunol 2005 6: 1087-1095.

9. Ninomiya-Tsuji J, Kishimoto K, Hiyama A, Inoue J, Cao Z, Matsumoto K. The kinase TAK1 can activate the NIK-I kappaB as well as the MAP kinase cascade in the IL-1 signalling pathway. Nature 1999; 398: 252-256.

10. Tan SH, Pal M, Tan MJ, Wong MHL, Tam FU, Teo JWT et al. Regulation of cell proliferation and migration by TAK1 via transcriptional control of von Hippel-Lindau tumor suppressor. J Biol Chem 2009; 284: 18047-18058.

11. Chong HC, Tan MJ, Philippe V, Tan SH, Tan CK, Ku CW et al. Regulation of epithelialmesenchymal IL-1 signaling by PPARbeta/delta is essential for skin homeostasis and wound healing. J Cell Biol 2009; 184: 817-831.
12. Page A, Navarro M, Garín M, Pérez $P$, Casanova ML, Moreno $R$ et al. IKKbeta leads to an inflammatory skin disease resembling interface dermatitis. J Invest Dermatol 2010; 130: 1598-1610.

13. Pasparakis M, Courtois G, Hafner M, Schmidt-Supprian M, Nenci A, Toksoy A et al. TNF-mediated inflammatory skin disease in mice with epidermis-specific deletion of IKK2. Nature 2002; 417: 861-866.

14. Sayama K, Hanakawa $Y$, Nagai $H$, Shirakata $Y$, Dai $X$, Hirakawa $S$ et al. Transforming growth factor-beta-activated kinase 1 is essential for differentiation and the prevention of apoptosis in epidermis. J Biol Chem 2006; 281: 22013-22020.

15. Omori E, Morioka S, Matsumoto $\mathrm{K}$, Ninomiya-Tsuji J. TAK1 regulates reactive oxygen species and cell death in keratinocytes, which is essential for skin integrity. J Biol Chem 2008; 283: 26161-26168.

16. Carroll JM, Albers KM, Garlick JA, Harrington R, Taichman LB. Tissue- and stratumspecific expression of the human involucrin promoter in transgenic mice. Proc Natl Acad Sci USA 1993; 90: 10270-10274.

17. Thrash BR, Menges CW, Pierce RH, McCance DJ. AKT1 provides an essential survival signal required for differentiation and stratification of primary human keratinocytes. J Biol Chem 2006; 281: 12155-12162.

18. Lev S, Givol D, Yarden Y. Interkinase domain of kit contains the binding site for phosphatidylinositol 3' kinase. Proc Natl Acad Sci USA 1992; 89: 678-682.

19. Blume-Jensen $P$, Janknecht $R$, Hunter $T$. The kit receptor promotes cell survival via activation of PI 3-kinase and subsequent Akt-mediated phosphorylation of Bad on Ser136. Curr Biol 1998; 8: 779-782.

20. Di-Poï N, Tan NS, Michalik L, Wahli W, Desvergne B. Antiapoptotic role of PPARbeta in keratinocytes via transcriptional control of the Akt1 signaling pathway. Mol Cell 2002; 10: 721-733.

21. Taylor WE, Najmabadi $H$, Strathearn M, Jou NT, Liebling M, Rajavashisth $T$ et al. Human stem cell factor promoter deoxyribonucleic acid sequence and regulation by cyclic $3^{\prime}, 5^{\prime}$-adenosine monophosphate in a Sertoli cell line. Endocrinology 1996; 137 : 5407-5414.

22. Omori E, Morioka S, Matsumoto K, Ninomiya-Tsuji J. TAK1 regulates reactive oxygen species and cell death in keratinocytes, which is essential for skin integrity. J Biol Chem 2008; 283: 26161-26168.

23. Kamata $\mathrm{H}$, Honda SI, Maeda S, Chang L, Hirata $\mathrm{H}$, Karin M. Reactive oxygen species promote TNFalpha-induced death and sustained JNK activation by inhibiting MAP kinase phosphatases. Cell 2005; 120: 649-661.

24. Brownlee M. Biochemistry and molecular cell biology of diabetic complications. Nature 2001; 414: 813-820.

25. Finkel T, Serrano M, Blasco MA. The common biology of cancer and ageing. Nature 2007; 448: $767-774$

26. Nathan C. Points of control in inflammation. Nature 2002; 420: 846-852.

27. Morioka S, Omori E, Kajino T, Kajino-Sakamoto R, Matsumoto K, Ninomiya-Tsuji J. TAK1 kinase determines TRAIL sensitivity by modulating reactive oxygen species and cIAP. Cell Death Differ 2009; 28: 2257-2265.

28. Ashman LK. The biology of stem cell factor and its receptor C-kit. Int J Biochem Cell Biol 1999; 31: 1037-1051.

29. Grabbe J, Welker P, Rosenbach T, Nürnberg W, Krüger-Krasagakes S, Artuc M et al. Release of stem cell factor from a human keratinocyte line, HaCaT, is increased in differentiating versus proliferating cells. J Invest Dermatol 1996; 107: 219-224.

30. Morita E, Lee DG, Sugiyama M, Yamamoto S. Expression of c-kit ligand in human keratinocytes. Arch Dermatol Res 1994; 286: 273-277.

31. Peters EMJ, Maurer M, Botchkarev VA, Jensen KD, Welker P, Scott GA et al. Kit is expressed by epithelial cells in vivo. J Invest Dermatol 2003; 121: 976-984.

32. Shilov VN, Sergienko VI. Oxidative stress in keratinocytes as an etiopathogenetic factor of psoriasis. Bull Exp Biol Med 2000; 129: 309-313.

33. Basset-Séguin N, Escot C, Molès JP, Blanchard JM, Kerai C, Guilhou JJ. C-fos and c-jun proto-oncogene expression is decreased in psoriasis: an in situ quantitative analysis. J Invest Dermatol 1991; 97: 672-678.

34. Tovar-Castillo LE, Cancino-Díaz JC, García-Vázquez F, Cancino-Gómez FG, León-Dorantes G, Blancas-González $\mathrm{F}$ et al. Under-expression of $\mathrm{VHL}$ and overexpression of HDAC-1, HIF-1alpha, LL-37, and IAP-2 in affected skin biopsies of patients with psoriasis. Int J Dermatol 2007; 46: 239-246.

35. Zenz R, Eferl R, Kenner L, Florin L, Hummerich L, Mehic D et al. Psoriasis-like skin disease and arthritis caused by inducible epidermal deletion of Jun proteins. Nature 2005; 437: 369-375.

36. Chang HY, Sneddon JB, Alizadeh AA, Sood R, West RB, Montgomery K et al. Gene expression signature of fibroblast serum response predicts human cancer progression: similarities between tumors and wounds. PLOS Biol 2004; 2: E7.

37. Coussens LM, Werb Z. Inflammation and cancer. Nature 2002; 420: 860-867.

38. Liou GY, Storz P. Reactive oxygen species in cancer. Free Radic Res 2010; 44: 479-496.

39. IJpenberg A, Tan NS, Gelman L, Kersten S, Seydoux J, Xu J et al. In vivo activation of PPAR target genes by RXR homodimers. EMBO J 2004; 23: 2083-2091. 